\title{
Bid-Ask Spread Decomposition and Information Asymmetry of Firms Cross-Listed in the London and New York Exchanges
}

\author{
Robin Hang Luo \\ Dept. of Business Administration, Faculty of Business, ALHOSN University, Abu Dhabi, \\ UAE
}

Tel: 971-2-4070-522Ｅ-mail: h.luo@alhosnu.ae

Received: Dec. 4, 2016

Accepted: Dec. 21, 2016 Published: Jan. 5, 2017

doi:10.5296/ifb.v4i1.10559

URL: http://dx.doi.org/10.5296/ifb.v4i1.10559

\begin{abstract}
This paper compares the effective bid-ask spread and examines the decomposition of spread in the London Stock Exchange (LSE) and New York Stock Exchange (NYSE). Results indicate that order persistence cost is generally higher in NYSE than in LSE while order processing cost in NYSE is lower, and higher proportion of the bid-ask spread is directly related to the information inefficiency in LSE.
\end{abstract}

Keywords: Bid-ask spread, Adverse selection, Order persistence, Order processing, Information asymmetry 


\section{Introduction}

A large number of companies, especially those with international operations, are now cross-listed in multiple stock exchanges. A trend of increasing numbers of stocks listed in foreign exchanges has been detected by Pagano, Röell, \& Zechner (2002) among many others. According to the New York Stock Exchange (NYSE), total market capitalization and total generated volume on non-US listings has increased tremendously since 1990s (Note 1). The purpose of this paper is not to study the rationalities and impacts of cross-listing itself though enormous interest and attention has been drawn to the investigation of these issues. We view the cross-listing of stocks in different countries as a golden opportunity to examine the information efficiency and information asymmetry of the market.

Ten large multinational corporations (MNCs) listed both in the London Stock Exchange (LSE) and NYSE are selected to conduct the research. We are able to find evidence of information asymmetry by checking the different patterns in their bid-ask spreads on the two exchanges. Among the models in investigating the market micro-structure, we follow the one developed by Lin, Sanger, \& Booth (1995) to decompose the bid-ask spread into three different components to further clarify the components which are closely related to information efficiency.

The most significant contribution of this paper is the extension of the Lin, Sanger, and Booth's model (LSB model) to decompose bid-ask spread on cross-listed stocks for information efficiency examination purpose. Although the LSB model has been widely used in different perspectives and a large amount of researches have been done on cross-listing, for instance, Venkataraman (2001)'s analysis on the execution costs on the Paris and New York exchanges, the combination of these two is a relatively new experiment. And the existence of overlapping trading time of these two markets gives us a good opportunity to investigate the variation of the bid-ask spread pattern during the day.

The present study should be of particular interest to the regulators that are considering the design of trading structures and investors that are trading on multiple markets as we report two interesting findings. First, the order persistence cost is generally higher in NYSE than LSE while the order processing cost in NYSE is lower. Second, higher proportion of the bid-ask spread is directly related to the information inefficiency in LSE rather than in NYSE. This study proceeds as follows. Section 2 provides a literature review in both bid-ask spread and cross-listing areas. Section 3 describes the methodology used in the study to decompose the bid-ask spread and estimate three components. Section 4 presents the data and empirical results. Section 5 summarizes the results.

\section{Literature Review}

\subsection{Bid-ask Spread Literature}

As a vital part in the market microstructure theory and a hot issue widely investigated by academics, many researches have been conducted on the bid-ask spread since the very early stage of the finance study focusing on the transaction costs. Demsetz (1968) provides a measurement for cost of transacting using empirical verifications based on his analysis on the specialists' bid-ask spread on NYSE to show "the extent to which the transactions costs are 
affected by the scale of trading", where the inverse relationship between the time rate of the transaction - namely the frequency and the spreads was considered as the centre piece of the transaction costs determinants. This theory was further extended into over-the-counter (OTC) transactions by Tinic \& West (1972).

Bid-ask spread study has become overwhelmingly popular in the academic world with various models developed in late 1980's through 1990's, which has a profound impact on the study in the recent years. Glosten \& Harris (1988) develop a model decomposing the bid-ask spread into two components: one due to asymmetric information and one due to inventory costs, specialist monopoly power, and clearing costs. They find that the hypothesis of information asymmetry as the cause of bid-ask spread cannot be rejected. George, Kaul, \& Nimalendran (1991) introduce a new approach to correct the downward bias found in previous bid-ask spread decomposition models by using information in both transaction prices and bid-ask quotes. In doing so they find a much smaller adverse selection component, non-existence of the inventory cost component, and thus a dominating order-processing component. Huang \& Stoll (1997), however, use two extensions to identify the small but significant inventory cost component and discover the interesting relationship between the trade size and the spread and its components. Lin et al. (1995) re-examine the relationship between the trade size and components of the bid-ask spread. Their findings demonstrate that the trade size has a positive relationship to adverse information component, an inverse relationship to the order processing cost component, and a positive relationship to the overall effective spread, in line with the prediction provided by previous studies. Madhavan, Richardson, \& Roomans (1997) develop another simple structural model to analyse intraday patterns of the bid-ask spreads. Their model incorporates four parameters for the determination of the transaction costs: the asymmetric information parameter, the cost of supplying liquidity, the probability a transaction takes place inside the spread, and the autocorrelation of the order flow.

Most of the existing studies are based on the empirical evidence from U.S. market, which is a dealer's market. Thus, there are more applications and empirical tests of these models in order-driven markets recently to extend the study on the bid-ask spread. For instance, Brockman \& Chung (1999) conduct a study on Hong Kong market; De Jong et al. (1996) examine this issue on the Paris Bourse. Ahn, Cai, Hamao, \& Ho (2002) and Ahn, Cai, Hamao, \& Ho (2005)'s extensive studies on Japanese market reveal the different patterns in bid-ask spread and its components from those in U.S. market. In addition, more insights are provided for some emerging markets. For example, Visaltanachoti, Luo, \& Wang (2007) examine the performance of market order execution strategy in the Australian market based on three bid-ask spread forecasting models. Chan, Menkveld, \& Yang (2008) provide tests on the bid-ask spread components and their pattern and the implication for information asymmetry in the foreign B-Shares market in China.

\subsection{Cross-listing Literature}

In the last few decades, the term "cross-listing" has been increasingly mentioned as a result of the trend of more companies listing shares in multiple markets, which was observed and investigated by Pagano, Randl, Röell, \& Zechner (2001) and Pagano et al. (2002) among many others. The focus of these studies is on the transatlantic cross-listings in terms of their 
trend, preferred choices of cross listing and the performance pre- and post-cross listing.

Although the study on cross listed companies is relatively new due to the recent wave of globalisation, the argument and theories on the asset-pricing, transaction costs, and many other issues on the fragmented versus centralised markets have been long in existence. For instance, Hamilton (1979) examined the effect of segmented market trading on the price and return of stocks. Alexander, Eun, \& Janakiramanan (1987) attempted to solve the asset-pricing puzzle of dual-listed stocks on foreign market. A following empirical test proposed by Alexander, Eun, \& Janakiramanan (1988) was used to justify the theory that cross listing tends to result in a reduction in the expected return, which was in line with the classic argument for a centralised market to reduce the costs and to enhance the market efficiency. Nevertheless, there is an inevitable trend among researchers building models to justify the fragmented trading by providing proofs of an existing equilibrium in fragmented market including Chowdhry \& Nanda (1991) and Biais (1993). Further studies on the price pattern and the implied information efficiency was conducted by Hasbrouck (1995) to investigate the price discovery for stocks listed on NYSE and other regional markets. Following Hasbrouck (1995)'s approach, Frijns, Gilbert, \& Tourani-Rad (2010) assess information shares and conditional information shares of a sample of bilateral cross-listings in Australia and New Zealand, and Frijns, Gilbert, \& Tourani-Rad (2015) examine the determinants of price discovery for Canadian firms cross-listed in the U.S. markets.

Unlike Hasbrouck (1995), Werner \& Kleidon (1996) turn the attention to the British stocks cross-listed on U.S. and U.K. markets to analyse their intraday pattern, discovering the differences between overlapping and non-overlapping trading hours and drawing the conclusion of segmented order flow for cross-listed securities. Similar results are given by Menkveld (2008) in stating the existence of order splitting in different markets for such kind of stocks, who extends the Chowdhry \& Nanda (1991) model to overlapping markets to investigate the order splitting of investors in different markets and provides empirical tests on the chosen cross-listed British and Dutch stocks.

\section{Model and Empirical Result}

The present study follows the model developed by Lin et al. (1995), which can be used to decompose the bid-ask spread into three components: the adverse selection costs, the order persistence costs, and the order processing component (Note 2); and to further estimate the three components. Lin et al. (1995)'s method is used to conduct the present research having considered that their model effectively describes the transaction characteristics in an order driven market comparing to the models proposed in Glosten \& Harris (1988) and Madhavan et al. (1997).

Following Lin et al. (1995) and Huang \& Stoll (1997), we assume at time ${ }^{t}$ a sell order is executed at the bid price $P_{t}=B_{t}$. The expected transaction price in the next period is then $E_{t}\left(P_{t+1}\right)=\delta B_{t+1}+(1-\delta) A_{t+1}$, where $A_{t}$ and $B_{t}$ are ask quote and bid quote at time $t, \delta$ is the probability of the transaction continuation in the same direction, that is, a sell (or buy) 
order is followed by a sell (or buy) order, and $1-\delta$ is the probability of transaction direction change. Thus, the expected gross profit of the mark maker at time $t+1$ is

$$
E_{t}\left(P_{t+1}\right)-P_{t}=\delta\left(B_{t+1}-B_{t}\right)+(1-\delta)\left(A_{t+1}-B_{t}\right)
$$

As adverse information can be reflected by a trade at time $t$, the quote revision can be expressed as $B_{t+1}=B_{t}+\lambda z_{t}$ and $A_{t+1}=A_{t}+\lambda z_{t}$, where $0<\lambda<1$ reflects the quote revision by the market maker is a proportion of the total bid-ask spread due to the adverse selection. $M_{t}$ is the middle price, $M_{t}=\left(A_{t}+B_{t}\right) / 2 . Z_{t}=P_{t}-M_{t}$ is half of the effective bid-ask spread showing the driving order of the trade, where a sell-driven trade has $z_{t}<0$ and a buy-driven order trade has $z_{t}>0$ (Note 3). If trades are executed at the either the bid quote or the ask quote, which is a reasonable assumption according to the literature, the following derivation of Equation (1) exists:

$$
\begin{aligned}
& E_{t}\left(P_{t+1}\right)-P_{t}=\left[\delta B_{t+1}+(1-\delta) A_{t+1}\right]-P_{t} \\
& =\lambda z_{t}+(1-2 \delta)\left[\left(A_{t}+B_{t}\right) / 2-B_{t}\right]+\left[\left(A_{t}+B_{t}\right) / 2\right]-P_{t} \\
& =-(1-\lambda-\theta) z_{t}
\end{aligned}
$$

where $\theta=2 \delta-1$ represents the order persistence. If the buy orders and sell orders come into the market randomly, $\delta=0.5$ and $\theta=0$. Nevertheless, evidence has been found by researchers that orders tend to move in the same direction (Note 4). This pattern of order arrivals implies that $0.5<\delta<1$ and $0<\theta<1$.

The above statement is based on a sell order executed at bid price. Analogically, the same equation applies to a by order executed at ask price. The order processing costs can be viewed as a proportion of the total bid-ask spread, which is $\gamma=1-\lambda-\theta$.

We then use the following equations to obtain the estimations of three components relative to the bid-ask spread, $\lambda$ the adverse selection cost component, $\theta$ the order persistence component, and $\gamma$ the order processing component.

$$
M_{t+1}-M_{t}=\lambda z_{t}+\varepsilon_{t+1}
$$




$$
\begin{gathered}
z_{t+1}=\theta z_{t}+\eta_{t+1} \\
P_{t+1}-P_{t}=\left(M_{t+1}-M_{t}\right)+z_{t+1}-z_{t}=-\gamma z_{t}+\mu_{t+1}
\end{gathered}
$$

In the present analysis, we filter the raw data before applying the Lin et al. (1995)'s model. Since the model is based on continuous trades, over-night quotes are excluded at first. And due to the problem to choose the appropriate bid-ask spread for the first trade every day, the first trade for each day is excluded from the model as well. In the LSE data, trades of private auction are recorded but without price and volume, so they are also excluded. For the calculation of bid-ask spread for each trade, weighted average bid and ask quotes are used for NYSE data, since the volume for each quote is provided; while a simple average is used for London data due to the lack of volume for each quote. Furthermore, the dates on which at least one of the markets is closed are also excluded from the analysis.

\section{Data and Empirical Results}

\subsection{Data}

One-year intraday data from 1st July 2008 to 30th June 2009 are obtained from SIRCA for ten MNCs cross-listed in both NYSE and LSE (Note 5). The dataset contains following variables: date and time for each trade and quote, trade price and volume, price of each bid and ask quote (Note 6). A summary statistics for the data is reported in Table 1. 
Table 1. Descriptive statistics

\begin{tabular}{|c|c|c|c|c|c|c|c|c|}
\hline & Mean & Median & Min & $\operatorname{Max}$ & $I^{n}$ Quartile & $3^{\text {rit }}$ Quartile & Std Dev & Skewness \\
\hline \multicolumn{9}{|c|}{ Panel A: Price (daily) } \\
\hline $\mathrm{AZN}$ & 40.85 & 40.64 & 30.3 & 49.67 & 37.76 & 44.79 & 4.82 & -0.093 \\
\hline AZN.L & 2519 & 2529 & 2111 & 2918 & 2377 & 2646 & 176.40 & -0.127 \\
\hline BCS & 15.12 & 15.39 & 2.925 & 29.42 & 8.62 & 22.2 & 7.74 & 0.210 \\
\hline BARC.L & 222 & 227.8 & 51.33 & 395.6 & 144.9 & 295.3 & 94.43 & -0.017 \\
\hline BP & 48.46 & 47.15 & 34.3 & 68.11 & 43.11 & 52.4 & 7.46 & 0.666 \\
\hline BP.L & 495.5 & 503.4 & 382.3 & 575.8 & 475.7 & 518.9 & 33.17 & -0.680 \\
\hline CBY & 36.9 & 34.78 & 28.08 & 51.07 & 31.95 & 44.32 & 6.58 & 0.805 \\
\hline CBRY.L & 561.9 & 551.1 & 472.6 & 664.1 & 528.5 & 600.3 & 41.85 & 0.365 \\
\hline DEO & 58.73 & 55.88 & 41.42 & 76.46 & 52.69 & 69.87 & 9.65 & 0.327 \\
\hline DGE.L & 895.7 & 893.4 & 731.9 & 1060 & 853.5 & 940.9 & 68.36 & -0.116 \\
\hline GSK & 37.73 & 36.38 & 27.55 & 48.92 & 33.51 & 43.33 & 5.96 & 0.419 \\
\hline GSK.L & 1160 & 1186 & 1001 & 1327 & 1072 & 1233 & 86.84 & -0.276 \\
\hline $\mathrm{HBC}$ & 54.44 & 49 & 23.79 & 83.75 & 40.86 & 75.53 & 18.53 & 0.238 \\
\hline HSBA.L & 656.4 & 660 & 336.2 & 918.9 & 528.6 & 810.3 & 157.88 & -0.058 \\
\hline RTP & 196.7 & 163.4 & 62.15 & 464.6 & 106.5 & 273.2 & 110.31 & 0.909 \\
\hline RIO.L & 2872 & 2527 & 1067 & 5881 & 1850 & 3771 & 1286.80 & 0.749 \\
\hline UL & 23.65 & 23.28 & 17.19 & 29.98 & 21.68 & 26.99 & 3.25 & 0.089 \\
\hline ULVR.L & 1473 & 1462 & 1084 & 6439 & 1399 & 1508 & 338.45 & 13.415 \\
\hline VOD & 20.77 & 19.32 & 15.69 & 31.01 & 18.36 & 22.67 & 3.70 & 1.131 \\
\hline VOD.L & 127.5 & 126.4 & 100.9 & 157.2 & 119.2 & 135.2 & 10.72 & 0.327 \\
\hline \multicolumn{9}{|c|}{ Panel B: Daily Volume } \\
\hline AZN & 1789 & 1605 & 0 & 8271 & 1171 & 2250 & 940.75 & 2.323 \\
\hline AZN.L & 6515 & 6064 & 918.6 & 18100 & 4712 & 7810 & 2736.42 & 1.232 \\
\hline BCS & 3627 & 2559 & 0 & 24490 & 1442 & 4683 & 3429.41 & 2.496 \\
\hline BARC.L & 86640 & 70430 & 3741 & 418300 & 50530 & 102900 & 58118.90 & 2.123 \\
\hline BP & 7916 & 7433 & 0 & 19600 & 5966 & 9415 & 2787.66 & 0.789 \\
\hline BP.L & 64420 & 58410 & 8592 & 184600 & 44740 & 77300 & 28510.74 & 1.264 \\
\hline CBY & 438.7 & 363.7 & 0 & 1942 & 257.6 & 519.3 & 284.70 & 2.025 \\
\hline CBRY.L & 6564 & 5675 & 1140 & 18740 & 4351 & 8221 & 3222.58 & 1.292 \\
\hline DEO & 996.9 & 911 & 0 & 3541 & 642.1 & 1186 & 508.65 & 1.630 \\
\hline DGE.L & 10200 & 8832 & 850.5 & 40140 & 7006 & 12460 & 5001.23 & 1.956 \\
\hline GSK & 2122 & 1970 & 0 & 6139 & 1518 & 2586 & 859.43 & 1.054 \\
\hline GSK.L & 16940 & 15200 & 2942 & 53770 & 12330 & 20560 & 7384.29 & 1.576 \\
\hline HBC & 3276 & 2773 & 0 & 17010 & 1864 & 4084 & 2094.97 & 2.222 \\
\hline HSBA.L & 60820 & 50660 & 14480 & 204300 & 36850 & 71010 & 36216.25 & 1.920 \\
\hline RTP & 1027 & 907.7 & 0 & 4557 & 593.9 & 1295 & 673.75 & 1.899 \\
\hline RIO.L & 9645 & 8443 & 663.7 & 75260 & 5954 & 10860 & 6676.71 & 4.645 \\
\hline UL & 1377 & 1185 & 0 & 5193 & 891.7 & 1679 & 765.00 & 1.771 \\
\hline ULVR.L & 5299 & 4523 & 547.8 & 18020 & 3499 & 6297 & 2764.55 & 1.678 \\
\hline VOD & 4566 & 4148 & 0 & 22320 & 3069 & 5457 & 2366.30 & 2.556 \\
\hline VOD.L & 205600 & 178200 & 32080 & 1120000 & 143200 & 247500 & 113020.12 & 3.847 \\
\hline
\end{tabular}

Note. Prices are in US Dollar and British Pound respectively. Daily prices are volume weighted average prices.

Daily volume figures are in thousands.

Table 1 shows the descriptive statistics of daily weighted average price and daily trading volume for ten cross-listed stocks. Time-varying pattern of daily price and volume were plotted in Figure 1. Most stocks demonstrate a highly volatile and price declining pattern due to the impact of Global Financial Crisis in the sample period. Standard deviations of stocks listed in the LSE are obviously higher than those listed in the NYSE. It might be a signal of relative information inefficiency in the LSE but it needs further exploration. 

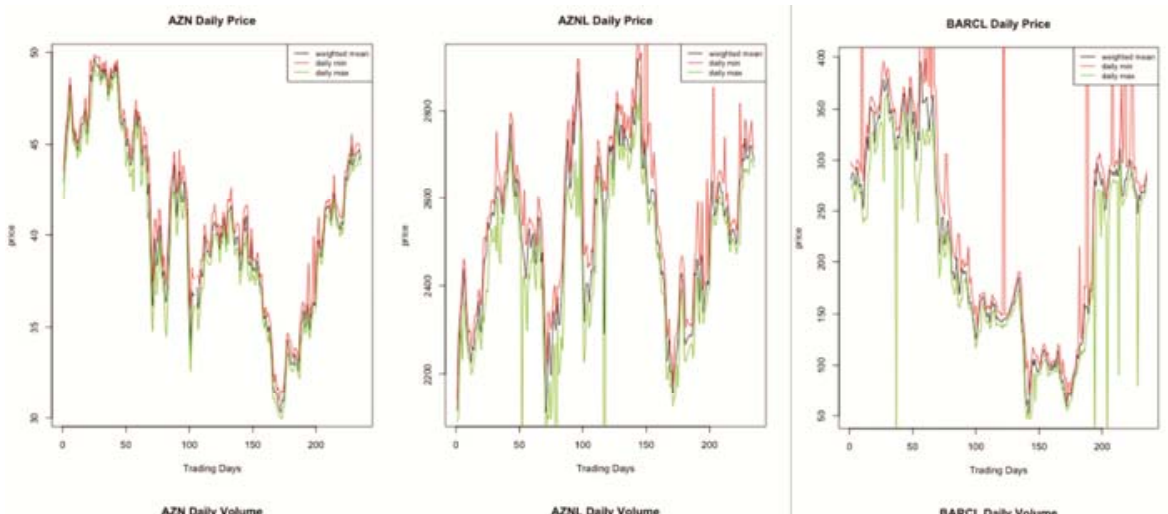

2017, Vol. 4, No. 1
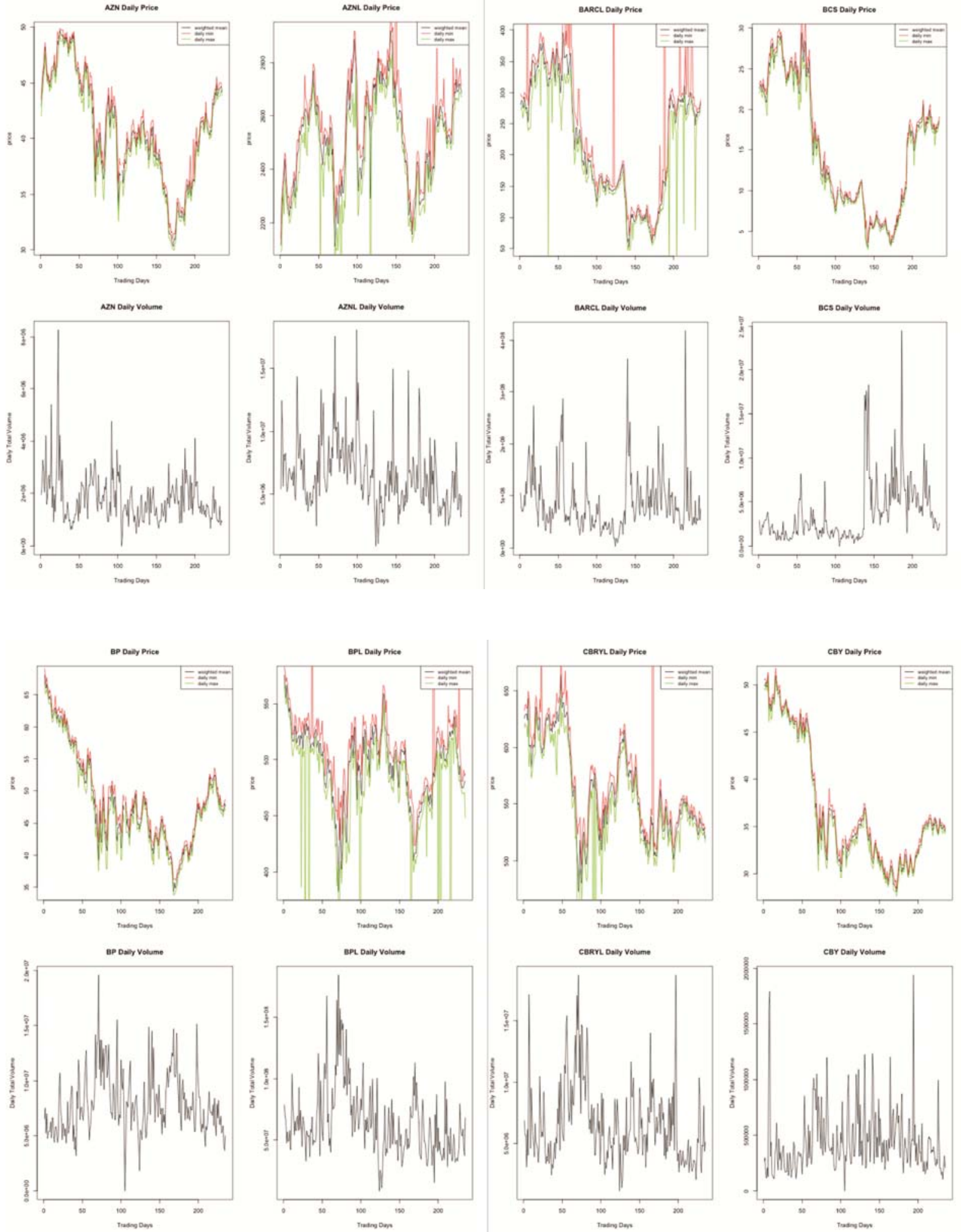


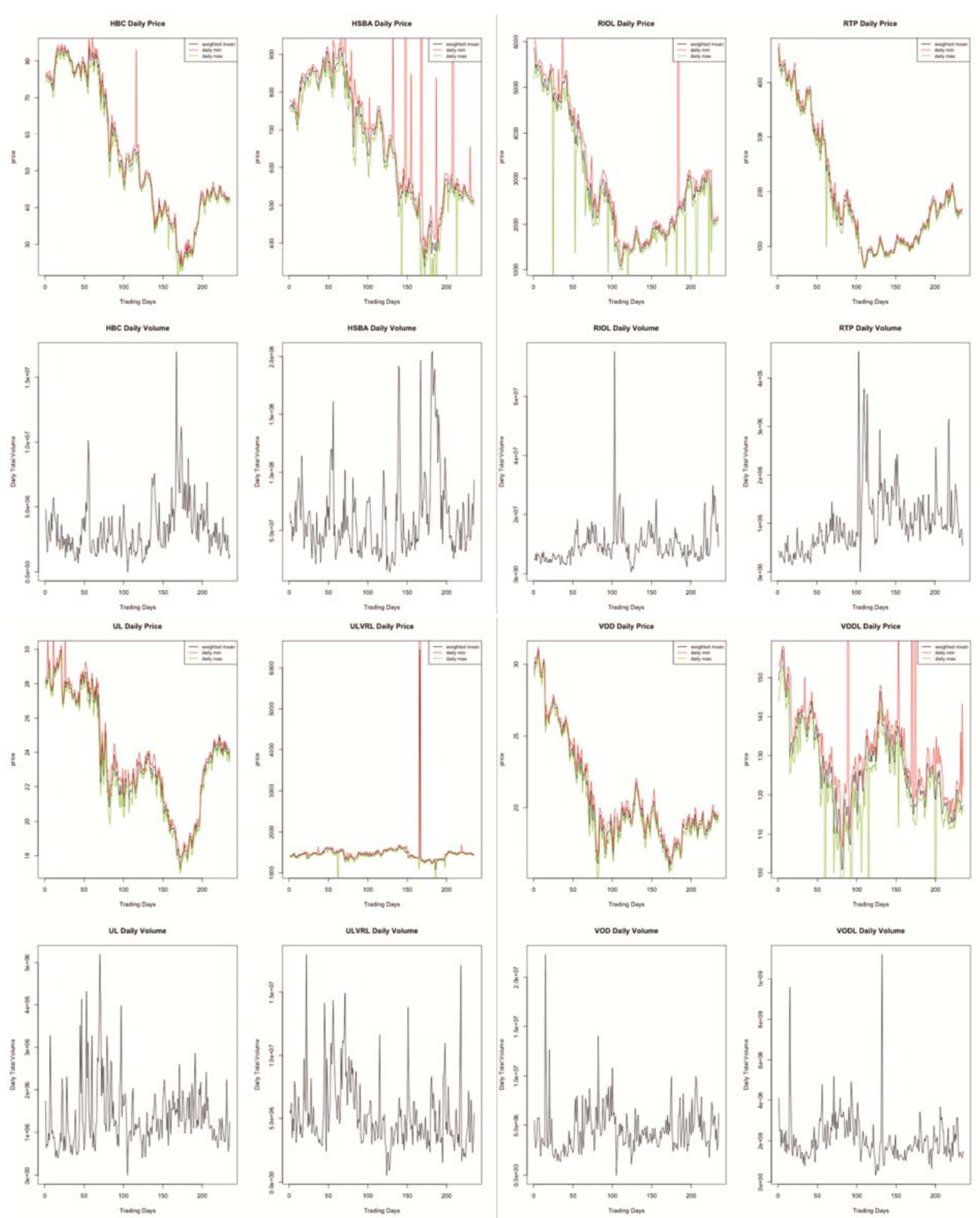



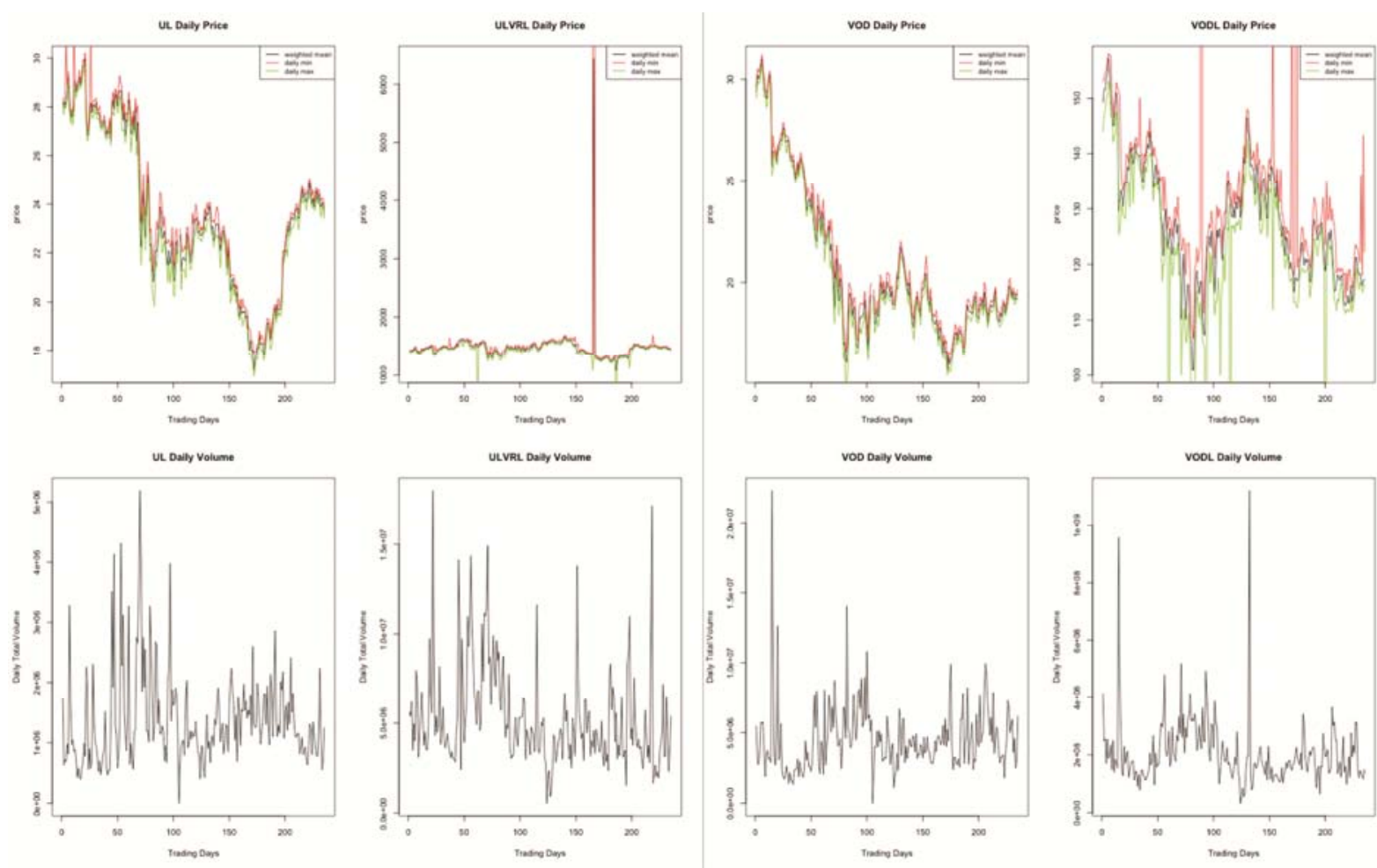

Figure 1. Plotted daily price and volume trend

Note. The black curve in the middle is the daily volume weighted average price, the green line is the daily maximum price, and the red line the daily minimum price.

The decomposition of three components of effective bid-ask spread of ten MNCs cross-listed in both NYSE and LSE is presented in Table 2. It is interesting to observe that order persistence parameters $(\theta)$ for stocks listed in NYSE are apparently higher than those listed in LSE. The highest average daily estimate of order persistence cost is $56.69 \%$ for GSK and lowest is $33.33 \%$ for RTP in NYSE, while the highest and lowest in LSE are $40.18 \%$ (ULVR.L) and 23.22\% (BARC.L), respectively (Note 7). This phenomenon indicates that the extent of order flow persistence in the NYSE is more salient which may have important implications on the short-term predictability of the stock price (Wyart, Bouchaud, Kockelkoren, Potters, \& Vettorazzo, 2008) and the aggregate daily order imbalances (Chordia, Roll, \& Subrahmanyam, 2002).

The estimates of order processing cost component $(\gamma)$ of the effective spread, however, demonstrate a different pattern. Order processing component is generally lower for stocks listed in NYSE than those listed in LSE. The highest average daily estimate of order processing cost is $35.47 \%$ for BP and lowest is $24.27 \%$ for CBY in NYSE, while the highest and lowest in LSE are 64.32\% (BARC.L) and 30.01\% (CBRY.L), respectively. Bessembinder \& Kaufman (1997)'s argue that NYSE quotes are for relatively large sizes at relatively narrow bid-ask spreads with lower order processing cost comparing to other non-NYSE markets in the U.S. Our result using the cross-listed samples supports Bessembinder \& Kaufman (1997)'s statement and extends the comparison the cross-exchange comparison of 
order processing cost to NYSE versus LSE.

Table 2. Estimates for three components of the bid-ask spread

\begin{tabular}{|l|c|c|c|}
\hline \multirow{2}{*}{} & \multicolumn{3}{|c|}{ Daily Estimates of Three Components of Bid-Ask Spread } \\
\cline { 2 - 4 } & $\lambda$ & $\theta$ & $\gamma$ \\
\hline AZN & $18.81 \%$ & $51.79 \%$ & $29.41 \%$ \\
\hline AZN.L & $25.22 \%$ & $33.10 \%$ & $41.68 \%$ \\
\hline BCS & $16.70 \%$ & $49.99 \%$ & $33.32 \%$ \\
\hline BARC.L & $12.46 \%$ & $23.22 \%$ & $64.32 \%$ \\
\hline BP & $12.27 \%$ & $52.26 \%$ & $35.47 \%$ \\
\hline BP.L & $15.62 \%$ & $28.24 \%$ & $56.14 \%$ \\
\hline CBY & $-102.88 \%$ & $178.61 \%$ & $24.27 \%$ \\
\hline CBRY.L & $31.54 \%$ & $38.44 \%$ & $30.01 \%$ \\
\hline DEO & $21.83 \%$ & $47.02 \%$ & $31.14 \%$ \\
\hline DGE.L & $24.34 \%$ & $37.08 \%$ & $38.58 \%$ \\
\hline GSK & $15.70 \%$ & $56.69 \%$ & $27.62 \%$ \\
\hline GSK.L & $19.63 \%$ & $34.61 \%$ & $45.77 \%$ \\
\hline HBC & $18.87 \%$ & $51.07 \%$ & $30.06 \%$ \\
\hline HSBA.L & $17.65 \%$ & $27.45 \%$ & $54.90 \%$ \\
\hline RTP & $33.33 \%$ & $33.33 \%$ & $33.33 \%$ \\
\hline RIO.L & $13.52 \%$ & $26.48 \%$ & $59.99 \%$ \\
\hline UL & $18.92 \%$ & $51.81 \%$ & $29.27 \%$ \\
\hline ULVR.L & $25.50 \%$ & $40.18 \%$ & $34.32 \%$ \\
\hline VOD & $11.08 \%$ & $62.40 \%$ & $26.52 \%$ \\
\hline VOD.L & $14.88 \%$ & $30.03 \%$ & $55.09 \%$ \\
\hline & & & \\
\hline & & & \\
\hline
\end{tabular}

Table 3. T-Statistics on effective bid-ask spread and its components

\begin{tabular}{|l|l|l|l|l|}
\hline Stocks & Spread and Components & T-Stats & P-value & Mean Difference \\
\hline \multirow{4}{*}{ AZN / AZN.L } & Total Spread & -3.288 & 0.001 & -15.098 \\
\cline { 2 - 5 } & $\lambda$ & -10.628 & 0.000 & -0.189 \\
\cline { 2 - 5 } & $\theta$ & 6.254 & 0.000 & 0.124 \\
\cline { 2 - 5 } & $\gamma$ & -4.336 & 0.000 & -0.252 \\
\hline \multirow{3}{*}{ BCS / BARC.L } & Total Spread & 1.000 & 0.318 & 10.259 \\
\cline { 2 - 5 } & $\lambda$ & -18.242 & 0.000 & -0.267 \\
\cline { 2 - 5 } & $\theta$ & 16.991 & 0.000 & 0.310 \\
\cline { 2 - 5 } & $\gamma$ & -5.833 & 0.000 & -0.263 \\
\hline \multirow{3}{*}{ BP / BP.L } & Total Spread & -1.005 & 0.316 & -4.644 \\
\cline { 2 - 5 } & $\lambda$ & -17.527 & 0.000 & -0.241 \\
\cline { 2 - 5 } & $\theta$ & 12.798 & 0.000 & 0.209 \\
\cline { 2 - 5 } & $\gamma$ & -10.565 & 0.000 & -0.257 \\
\hline
\end{tabular}




\begin{tabular}{|c|c|c|c|c|}
\hline \multirow[t]{4}{*}{ CBY / CBRY.L } & Total Spread & 0.926 & 0.355 & 4.944 \\
\hline & $\lambda$ & -1.393 & 0.165 & -1.399 \\
\hline & $\theta$ & 3.063 & 0.002 & 0.056 \\
\hline & $\gamma$ & -1.381 & 0.301 & -0.233 \\
\hline \multirow[t]{4}{*}{ DEO / DGE.L } & Total Spread & -0.997 & 0.320 & -20.827 \\
\hline & $\lambda$ & 7.089 & 0.000 & 0.100 \\
\hline & $\theta$ & -4.681 & 0.000 & -0.075 \\
\hline & $\gamma$ & 1.520 & 0.189 & 0.237 \\
\hline \multirow[t]{4}{*}{ GSK / GSK.L } & Total Spread & -1.073 & 0.285 & -82.557 \\
\hline & $\lambda$ & -13.337 & 0.000 & -0.220 \\
\hline & $\theta$ & 10.518 & 0.000 & 0.181 \\
\hline & $\gamma$ & -1.780 & 0.098 & -0.155 \\
\hline \multirow[t]{4}{*}{ HBC / HSBA.L } & Total Spread & -1.004 & 0.316 & -45.620 \\
\hline & $\lambda$ & 15.193 & 0.000 & 0.237 \\
\hline & $\theta$ & -13.984 & 0.000 & -0.250 \\
\hline & $\gamma$ & 6.386 & 0.000 & 0.197 \\
\hline \multirow[t]{4}{*}{ RTP / RIO.L } & Total Spread & 1.117 & 0.265 & 19.474 \\
\hline & $\lambda$ & -7.616 & 0.000 & -0.250 \\
\hline & $\theta$ & 13.172 & 0.000 & 0.389 \\
\hline & $\gamma$ & -4.923 & 0.000 & -0.191 \\
\hline \multirow[t]{4}{*}{ UL / ULVR.L } & Total Spread & -1.021 & 0.308 & -24.25 \\
\hline & $\lambda$ & 5.275 & 0.000 & 0.119 \\
\hline & $\theta$ & -2.207 & 0.028 & -5.317 \\
\hline & $\gamma$ & 0.549 & 0.612 & 0.055 \\
\hline \multirow[t]{4}{*}{ VOD / VOD.L } & Total Spread & -1.001 & 0.318 & -55.405 \\
\hline & $\lambda$ & -23.702 & 0.000 & -0.322 \\
\hline & $\theta$ & 18.294 & 0.000 & 0.285 \\
\hline & $\gamma$ & -5.117 & 0.000 & -0.412 \\
\hline
\end{tabular}

The estimated result of adverse selection cost component $(\lambda)$ is ambiguous with six out of ten stocks have lower average estimate adverse information component and three out of ten stocks have higher average estimate $\lambda$. (Note 8) As both adverse selection component and order persistence component are more closely related to the information asymmetry, we further explore the mean difference of total effective bid-ask spread and its three components using two-sample t-test. The results of t-test are shown in Table 3. Almost all t-statistics of total effective bid-ask spread are insignificant while the t-statistics of adverse selection component and order persistence component are significant at $1 \%$ level. So we reject the null hypothesis and conclude that the means of adverse selection component and order persistence component in NYSE and LSE are different at the 1\% significance level. The t-test for the order processing cost component shows similar result but with seven out of ten stocks are significant at $1 \%$ level. We can conclude that NYSE has lower transaction cost relative to the 
share price than that in the LSE. The discrepancy might be explained by the different market structure.

The decomposition of effective bid-ask spread illustrates that higher proportion of the bid-ask spread is directly related to the information inefficiency in LSE rather than in NYSE. This result is consistent with Hasbrouck, Sofianos, \& Sosebee (1993) and in that market makers in NYSE help maintain narrow spreads and improve information efficiency.

\section{Conclusion}

This paper compares the effective bid-ask spread and its three components, namely the adverse selection component, the order persistence component, and the order processing component, of ten large MNCs cross-listed in the NYSE and LSE. Although most cross-listed stocks demonstrate a highly volatile and price declining pattern due to the impact of Global Financial Crisis, standard deviations of those listed in the LSE are obviously higher than those in the NYSE.

The decomposition of three components of effective bid-ask spread illustrates that the order persistence cost is generally higher in NYSE than LSE while the order processing cost in NYSE is lower than that in LSE. As the estimated result of adverse selection cost component is mixed, we further explore the mean difference of total effective bid-ask spread and its three components using two-sample t-test to better understand the information asymmetry in these two exchanges. The test result demonstrates that higher proportion of the bid-ask spread is directly related to the information inefficiency in LSE rather than in NYSE.

\section{References}

Ahn, H. J., Cai, J., Hamao, Y., \& Ho, R. Y. (2002). The components of the bid-ask spread in a limit-order market: evidence from the Tokyo Stock Exchange. Journal of Empirical Finance, 9(4), 399-430. http://dx.doi.org/10.1016/S0927-5398(02)00003-8

Ahn, H. J., Cai, J., Hamao, Y., \& Ho, R. Y. (2005). Adverse selection, brokerage coverage, and trading activity on the Tokyo Stock Exchange. Journal of Banking \& Finance, 29(6), 1483-1508. http://dx.doi.org/10.1016/j.jbankfin.2004.05.039

Alexander, G. J., Eun, C. S., \& Janakiramanan, S. (1987). Asset pricing and dual listing on foreign capital markets: A note. Journal of Finance, 42(1), 151-158.

http://dx.doi.org/10.1111/j.1540-6261.1987.tb02556.x

Alexander, G. J., Eun, C. S., \& Janakiramanan, S. (1988). International listings and stock returns: Some empirical evidence. Journal of Financial and Quantitative Analysis, 23(02), 135-151. http://dx.doi.org/10.2307/2330877

Bessembinder, H., \& Kaufman, H. M. (1997). A cross-exchange comparison of execution costs and information flow for NYSE-listed stocks. Journal of Financial Economics, 46(3), 293-319. http://dx.doi.org/10.1016/S0304-405X(97)00032-9

Biais, B. (1993). Price formation and equilibrium liquidity in fragmented and centralized markets. Journal of Finance, 48(1), 157-185. 
http://dx.doi.org/10.1111/j.1540-6261.1993.tb04705.x

Brockman, P., \& Chung, D. Y. (1999). Bid-ask spread components in an order-driven environment. Journal of Financial Research, 22(2), 227-246.

http://dx.doi.org/10.1111/j.1475-6803.1999.tb00724.x

Chan, K., Menkveld, A. J., \& Yang, Z. (2008). Information asymmetry and asset prices:

Evidence from the China foreign share discount. Journal of Finance, 63(1), 159-196.

http://dx.doi.org/10.1111/j.1540-6261.2008.01313.x

Choi, J. Y., Salandro, D., \& Shastri, K. (1988). On the estimation of bid-ask spreads: Theory and evidence. Journal of Financial and Quantitative Analysis, 23(2), 219-230.

http://dx.doi.org/10.2307/2330882

Chordia, T., Roll, R., \& Subrahmanyam, A. (2002). Order imbalance, liquidity, and market returns. Journal of Financial Economics, 65(1), 111-130.

http://dx.doi.org/10.1016/S0304-405X(02)00136-8

Chowdhry, B., \& Nanda, V. (1991). Multimarket trading and market liquidity. Review of Financial Studies, 4(3), 483-511. http://dx.doi.org/10.1093/rfs/4.3.483

De Jong, F., Nijman, T., \& Röell, A. (1996). Price effects of trading and components of the bid-ask spread on the Paris Bourse. Journal of Empirical Finance, 3(2), 193-213.

http://dx.doi.org/10.1016/0927-5398(95)00017-8

Demsetz, H. (1968). The cost of transacting. The Quarterly Journal of Economics, 33-53. http://dx.doi.org/10.2307/1882244

Frijns, B., Gilbert, A., \& Tourani-Rad, A. (2010). The dynamics of price discovery for cross-listed shares: Evidence from Australia and New Zealand. Journal of Banking \& Finance, 34(3), 498-508. http://dx.doi.org/10.1016/j.jbankfin.2009.08.014

Frijns, B., Gilbert, A., \& Tourani-Rad, A. (2015). The determinants of price discovery:

Evidence from US-Canadian cross-listed shares. Journal of Banking \& Finance, 59, 457-468. http://dx.doi.org/10.1016/j.jbankfin.2015.07.011

George, T. J., Kaul, G., \& Nimalendran, M. (1991). Estimation of the bid-ask spread and its components: A new approach. Review of financial studies, 4(4), 623-656.

http://dx.doi.org/10.1093/rfs/4.4.623

Glosten, L. R., \& Harris, L. E. (1988). Estimating the components of the bid/ask spread.

Journal of Financial Economics, 21(1), 123-142.

http://dx.doi.org/10.1016/0304-405X(88)90034-7

Hamilton, J. L. (1979). Marketplace fragmentation, competition, and the efficiency of the stock exchange. Journal of Finance, 34(1), 171-187.

http://dx.doi.org/10.1111/j.1540-6261.1979.tb02078.x

Hasbrouck, J. (1991). Measuring the information content of stock trades. Journal of Finance, 46(1), 179-207. http://dx.doi.org/10.1111/j.1540-6261.1991.tb03749.x 
Hasbrouck, J. (1995). One security, many markets: Determining the contributions to price discovery. Journal of Finance, 50(4), 1175-1199.

http://dx.doi.org/10.1111/j.1540-6261.1995.tb04054.x

Hasbrouck, J., \& Ho, T. S. (1987). Order arrival, quote behavior, and the return-generating process. Journal of Finance, 42(4), 1035-1048.

http://dx.doi.org/10.1111/j.1540-6261.1987.tb03926.x

Hasbrouck, J., Sofianos, G., \& Sosebee, D. (1993). New York Stock Exchange systems and trading procedures. Director, 212(998), 0310.

Huang, R. D., \& Stoll, H. R. (1997). The components of the bid-ask spread: A general approach. Review of financial studies, 10(4), 995-1034. http://dx.doi.org/10.1093/rfs/10.4.995

Lin, J. C., Sanger, G. C., \& Booth, G. G. (1995). Trade size and components of the bid-ask spread. Review of financial studies, 8(4), 1153-1183. http://dx.doi.org/10.1093/rfs/8.4.1153

Madhavan, A., Richardson, M., \& Roomans, M. (1997). Why do security prices change? A transaction-level analysis of NYSE stocks. Review of financial studies, 10(4), 1035-1064. http://dx.doi.org/10.1093/rfs/10.4.1035

Menkveld, A. J. (2008). Splitting orders in overlapping markets: A study of cross-listed stocks. Journal of Financial Intermediation, 17(2), 145-174.

http://dx.doi.org/10.1016/j.jfi.2007.05.004

Pagano, M., Röell, A. A., \& Zechner, J. (2002). The geography of equity listing: why do companies list abroad? Journal of Finance, 57(6), 2651-2694.

http://dx.doi.org/10.1111/1540-6261.00509

Pagano, M., Randl, O., Röell, A. A., \& Zechner, J. (2001). What makes stock exchanges succeed? Evidence from cross-listing decisions. European Economic Review, 45(4), 770-782. http://dx.doi.org/10.1016/S0014-2921(01)00132-5

Tinic, S. M., \& West, R. R. (1972). Competition and the pricing of dealer service in the over-the-counter stock market. Journal of Financial and Quantitative Analysis, 7(03), 1707-1727. http://dx.doi.org/10.2307/2329797

Venkataraman, K. (2001). Automated versus floor trading: An analysis of execution costs on the Paris and New York exchanges. Journal of Finance, 56(4), 1445-1485.

http://dx.doi.org/10.1111/0022-1082.00375

Visaltanachoti, N., Luo, H., \& Wang, D. (2007). Performance of market order execution strategy: the Australian evidence. Applied Economics Letters, 14(13), 945-949.

http://dx.doi.org/10.1080/13504850600705927

Werner, I. M., \& Kleidon, A. W. (1996). UK and US trading of British cross-listed stocks: An intraday analysis of market integration. Review of financial studies, 9(2), 619-664.

http://dx.doi.org/10.1093/rfs/9.2.619

Wyart, M., Bouchaud, J. P., Kockelkoren, J., Potters, M., \& Vettorazzo, M. (2008). Relation 


\section{Macrothink}

between bid-ask spread, impact and volatility in order-driven markets. Quantitative Finance, 8(1), 41-57. http://dx.doi.org/10.1080/14697680701344515

\section{Notes}

Note 1. See www.nysedata.com

Note 2. The order persistence component can be caused by many factors, for example splitting of orders, or adjusting to limit orders slowly when new information released (Lin et al., 1995).

Note 3. The implication here is that a trade price more close to bid price is recognised as sell-driven, and the trade price more close to ask price is recognised as buy-driven.

Note 4. Hasbrouck and Ho (1987), Choi, Salandro, and Shastri (1988), and Hasbrouck (1991) show that buy orders tend to follow by orders, and sell orders.

Note 5. See appendix 1 for the list of companies.

Note 6. NYSE data also contains volume for each quote.

Note 7. The order persistent component of CBY is excluded in the comparison as it exceeds $100 \%$.

Note 8. The adverse selection component of CBY is excluded in the comparison as it is negative and becomes meaningless. 


\section{Macrothink}

\section{Appendix}

\section{Appendix 1. List of Sample Firms}

\begin{tabular}{|l|l|l|}
\hline \multirow{2}{*}{ Name } & Symbol & Exchange \\
\hline \multirow{2}{*}{ Barclays PLC } & AZN & NYSE \\
\cline { 2 - 3 } & AZN.L & LSE \\
\hline \multirow{2}{*}{ BP PLC } & BCS & NYSE \\
\cline { 2 - 3 } & BARC.L & LSE \\
\hline \multirow{2}{*}{ Cadbury Schweppes PLC } & BP & NYSE \\
\cline { 2 - 3 } & BP.L & LSE \\
\hline \multirow{2}{*}{ Diageo plc } & CBY & NYSE \\
\cline { 2 - 3 } & CBRY.L & LSE \\
\hline \multirow{2}{*}{ GlaxoSmithKline PLC } & DEO & NYSE \\
\cline { 2 - 3 } & DGE.L & LSE \\
\hline \multirow{2}{*}{ HSBC Holdings PLC } & GSK & NYSE \\
\cline { 2 - 3 } & GSK.L & LSE \\
\hline \multirow{2}{*}{ Rio Tinto PLC } & HBC & NYSE \\
\cline { 2 - 3 } & HSBA.L & LSE \\
\hline \multirow{2}{*}{ Unilever PLC } & RTP & NYSE \\
\cline { 2 - 3 } & RIO.L & LSE \\
\hline \multirow{2}{*}{ Vodafone Group PLC } & UL & NYSE \\
\cline { 2 - 3 } & ULVR.L & LSE \\
\hline & VOD & NYSE \\
\cline { 2 - 3 } & VOD.L & LSE \\
\hline & & \\
\hline
\end{tabular}

\section{Copyright Disclaimer}

Copyright for this article is retained by the author(s), with first publication rights granted to the journal. This is an open-access article distributed under the terms and conditions of the Creative Commons Attribution license (http://creativecommons.org/licenses/by/3.0/). 